ISSN 1112-9867

Available online at

http://www.jfas.info

\title{
EXAMINE THE IMPACT OF THE CHANGES IN STYLE OF POL YMER FIBERS CONCRETE FULL OF STRENGTH
}

\author{
P. Kavandi ${ }^{*}$ and S. Abdollahi
}

Department of civil engineering, Zanjan Branch, Islamic Azad University, Zanjan, Iran

Published online: 05 June 2016

\begin{abstract}
Today, an increase of strength and form any more uses the most important and most construction materials , concrete, a large number of researchers and practitioners concern in this paper also based on experiments impact of the fibers changes took place in the style of the strength of concrete full - reinforced polymer fibers has been studied .

Study on the impact of the fibers change shows that in order to achieve high strength of concrete Fiber major factors and significant change of the fibers, including a significant impact on the maximum tension is obtained. Also compared the style of the strength full - reinforced polymer fibers with optimum length concluded with concrete normal as a result of the change, and more tangible face was visible. In this study several tests on various types of light - fiber - reinforced concrete strength and different percentages of fiber and results figures and tables application.
\end{abstract}

Keywords: Fiber concrete polymer fibers; concrete style; full of strength; the percentage of polymer fibers in concrete; the polymer fibers in concrete.

Author Correspondence, e-mail: pouya.kavandi@yahoo.com

doi: http://dx.doi.org/10.4314/jfas.8vi2s.27

Journal of Fundamental and Applied Sciences is licensed under a Creative Commons Attribution-NonCommercial 4.0 International License. Libraries Resource Directory. We are listed under Research Associations category. 


\section{INTRODUCTION}

Today, in our country with respect to administrative and economic issues, the use of concrete structures significantly different development while still permeability concrete due to the inherent porosity of the main problems hydraulic structures in civilian installations, industrial and sea which is not only destroyed but concrete with steel reinforcement corrosion caused so much damage to buildings . Various methods, including the use of different types of food additives to reduce the influence of the concrete provided but in general the phenomenon of permeability much in control by researchers recently various steps to control the cracking, mechanical properties, and stress distributions ... with the use of fiber and as fibers can bridge nodes in concrete structure and sewing precursors it under control, the interests of all kinds of Turks and reduce be concrete permeability (Hussein race, $6: 1393$ ) and its application in concrete construction structures as one of the basic interests in the construction industry predilection industry to use concrete material has led to a lot of research on reforming and improving its disadvantages. One of the famous weaknesses in concrete, crisp and lack of form concrete material, which is currently reinforcing concrete members by the steel reinforcement of fiber and discrete attempt to overcome, is concerned. ( Khairi,Qassemi, Dehghan, $1: 2009$ ), one of the most full use of synthetic polymer fibers, which I often face around two jackets, armed and for strengthening the concrete and reinforcement. What polymers armed as key and a restorative or resistant construction properties, such as light weight ,high strength, weight, speed up strength operations, lack of machinery and equipment, in particular - resistant to corrosion weather conditions and economical total operation and simplicity are operation ( passers - by, new castle , Adili $3: 1387$ ) In this paper purports to examine the behavior of full - style - reinforced polymer fibers strength to the results of this study the effects of the study.

\section{THE STRENGTH OF CONCRETE}

There are different types of light aggregates, raising the possibility that the concrete with specific gravity 300 to 1850 between the 3 and strength to $400 \mathrm{~kg} \mathrm{~cm}$ square meters and sometimes even higher. With a large amount of cement consumption can be strength to 600 square centimeter $\mathrm{kg}$. (ramezanpour, Shah theoretical 310: 1383) with a range of light weight concrete), based on a variety of light aggregates (classified ACI, concrete 1600 in this study . in the light of seeds of most are in the event that a significant differences in concrete characteristics and the mother of 
this study with the characteristics of the control of the grain seeds, artificial called lika that the expansion of clay . Rossi aggregate expanded, when ash with the process of the gob produced and has a solid $650900 \mathrm{~kg}$ weight to the cubic meters and when the rotating furnaces, has a volume $30050 \mathrm{~kg}$ weight to the cubic meters. (ramezanpour : 1383367 , Shah theoretical ) in choosing the type of cement is one of the most important is that the concrete in cold weather to cement with a rapid increase in the heat of the hydrated and planning for the concrete in hot weather and planning to cement concrete massive with low hydrate heat. (ramezanpour : 1383 367 , Shah theoretical) as well as the ratio of water in the study of cement relations in the mixed with the same components are made clear, and type of cement used, the strength increases, the possibility of chemical attacks and thermal, cement 2 brigade, which is one of the country and with specific gravity 3150 .

constructive architects and engineers building in the world with the use of concrete in various parts of the building to alleviate the weight of the building to directly associate ( in terms of style especially this kind of concrete) to save energy and indirectly (in terms of dielectric of this type of concrete in front of the hot and cold and as a result of the decline in the amount of fuel ), economically today and important steps . (abdgahi, golkarian, Tavakoli , 2 : 1388)

\section{FIBER - REINFORCED CONCRETE}

According to the definition of ACI544.IR -82, concrete armed with fiber or concrete Fiber, is concrete hydraulic cement, fine - grained stone materials or fine - grained and large grain and individual fibers and continuous, is built. Fiber may be natural like asbestos, specific types of hemp , and Cellulose, or of products like glass, steel, carbon and polymer ( such as polypropylene orKevlar). Poor, Shah (Ramadan theoretical 435: 1383) In this study, arming concrete with significant results, fiber, like the strength strain and preventing the development of the Turks and transfer to increase tension within a point that can change with regard to the results of a larger forms. in this case in concrete, fiber, preventing the concrete and instantaneous failure to control the behavior of concrete and stress - strain curve with mullah slope. The strength of concrete, of course, reinforced concrete benefits of fiber can light up strength and the behavior of control simultaneously.

\subsection{The role of the fibers in concrete}


Benefits and the important role of the fibers in concrete Fiber caused most favorite engineers and designers. the possibility of employment in most areas of, the use of natural and cheap , low cost compared with high volume of operations and form it with geometric shapes rated their planed high - level strength and resistant to push and pull forces and the ability to attract energy and stability to cracking of the typical characteristics of this type of concrete .

According to all the results can be taken for the following reasons for the use of this type of concrete stated:

1 - Controlled the stress - strain curve slope

2 - Prevent rupture and destruction of the structure

3 - Weight loss (members)

4 - Reduce structural dimensions (to increase the useful)

5 - Cost reduction

Fiber types that are used in concrete can be classified as follows:

1 - Steel fibers Tensile with very high $1 \mathrm{~mm}$ in diameter and $5 \mathrm{~cm}$, Qatar $8 / 0$ and $6 \mathrm{~cm}$.

2 - Synthetic fibers to promote stability and concrete mechanical and performance, especially sharked are used.

3 - Glass fibers to equip the concrete and an increase in the use of chemical strength.

\begin{tabular}{|c|c|c|c|c|c|c|c|c|c|c|c|c|c|c|c|c|}
\hline number & 1 & 2 & 3 & 4 & 5 & 6 & 7 & 8 & 9 & 10 & 11 & $\begin{array}{l}1 \\
2\end{array}$ & 13 & 14 & $\begin{array}{l}1 \\
5\end{array}$ & 16 \\
\hline $\begin{array}{l}\text { Max. } \\
\text { tension }\end{array}$ & $\begin{array}{l}\underset{8}{0} \\
\stackrel{m}{+}\end{array}$ & 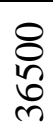 & $\begin{array}{l}8 \\
\infty \\
2 \\
\text { ते }\end{array}$ & $\begin{array}{l}8 \\
8 \\
\text { నे }\end{array}$ & ষ্ঠ & $\begin{array}{l}8 \\
\stackrel{n}{7} \\
\dot{7}\end{array}$ & $\begin{array}{l}\text { 8 } \\
\text { \&े } \\
\text { ले }\end{array}$ & ঙ্ণ & $\begin{array}{l}8 \\
\varnothing \\
n \\
n\end{array}$ & $\underset{\infty}{\infty}$ & $\frac{8}{\stackrel{8}{8}}$ & $\begin{array}{l}8 \\
\text { ㄱ. } \\
\text { m }\end{array}$ & $\underset{\substack{8 \\
\text { m }}}{\text { m }}$ & $\frac{\stackrel{\text { c }}{m}}{m}$ & $\begin{array}{l}8 \\
8 \\
\text { ㄴ } \\
\text { nి }\end{array}$ & 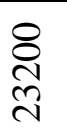 \\
\hline $\begin{array}{r}\text { Amoun } \\
t \quad \text { of } \\
\text { fiber }\end{array}$ & $\begin{array}{r}0 . \\
5\end{array}$ & 1 & $\begin{array}{l}1 . \\
5\end{array}$ & 2 & 2.5 & 0.5 & 1 & 1.5 & 2 & 2.5 & 0.5 & 1 & 1.5 & 2 & $\begin{array}{r}2 . \\
5\end{array}$ & - \\
\hline $\begin{array}{l}\text { Length } \\
\text { of fiber }\end{array}$ & 1 & 1 & 1 & 1 & 1 & 3 & 3 & 3 & 3 & 3 & 5 & 5 & 5 & 5 & 5 & - \\
\hline
\end{tabular}

As shown in Table results are being observed samples with an average of specific gravity 1600 $\mathrm{kg} / \mathrm{m} 33$ the fibers in various reviewed with respect to percent of fiber observed that the amount of tension. They also affected the changes that each sample to ordinary concrete ( 16 ). Given at 
the results in Table Fiber concrete at any time during the 4 tested separately in each experiment with changing percent of the maximum fiber variable tensions registered in this study maximum amount of tension in the fibers in $\%$ as a result of joint individual in the diagram in Annex registration and analysis. For example, in the diagram 1 , a maximum of tension in the fibers 1 and 3 and $5 \mathrm{~cm} 0.5$ with the amount of fiber \%, compared with every three tension may predicted that the maximum amount of the tension with concrete Fiber percent of the fibers, known in the fibers $3 \mathrm{~cm}$.

\section{THE RESULTS}

with the study and analyze the change in the value of the fiber $1 \%, 1.5 \%, 2 \%, 2.5 \%$ of achieving similar results that regardless of all other factors, such as the side ratio, the maximum amount of tension and concrete Fiber, it can be concluded the optimum length for fiber used in this kind of concrete, approximately $3 \mathrm{~cm}$ that, according to B 6 diagram, where tensions during the $3 \mathrm{~cm}$ in percent of the fibers, investigated, the optimum percent of fiber during the $3 \mathrm{~cm}$ as most of the articles and studies concluded, some about $0.5 \%$.

Compared with a maximum of tension with concrete Fiber, that the fiber at a length of $3 \mathrm{~cm}$ and the amount of fiber $1 \%$ per cent, with ordinary concrete in 7 chart compiled and scrutiny during the experiment, there was a significant difference between the maximum concrete tension and tension and the maximum concrete Fiber with most optimum concluded that can be observed under benefits for the concrete full style - reinforced polymer fibers strength to ordinary concrete: 1- Fiber- reinforced concrete relatively large strength than ordinary concrete in front of fatigue tensions.

2 - With regard to the stress curve of Fiber concrete was custom concluded that this kind of strength of concrete to more than ordinary concrete.

3- After occur cracks in a concrete Fiber cargo capability significantly from the ordinary concrete.

4- During loading, depending on the tolerances tensions and tensile strains considerable traction loads, it can be concluded that armed strength of concrete - style of polymer fibers in designs can be an effective application .

5- , depending on the cracking of concrete due to multiple Fiber (leave), it can be a significant effects in form and reliability of concrete structures . 


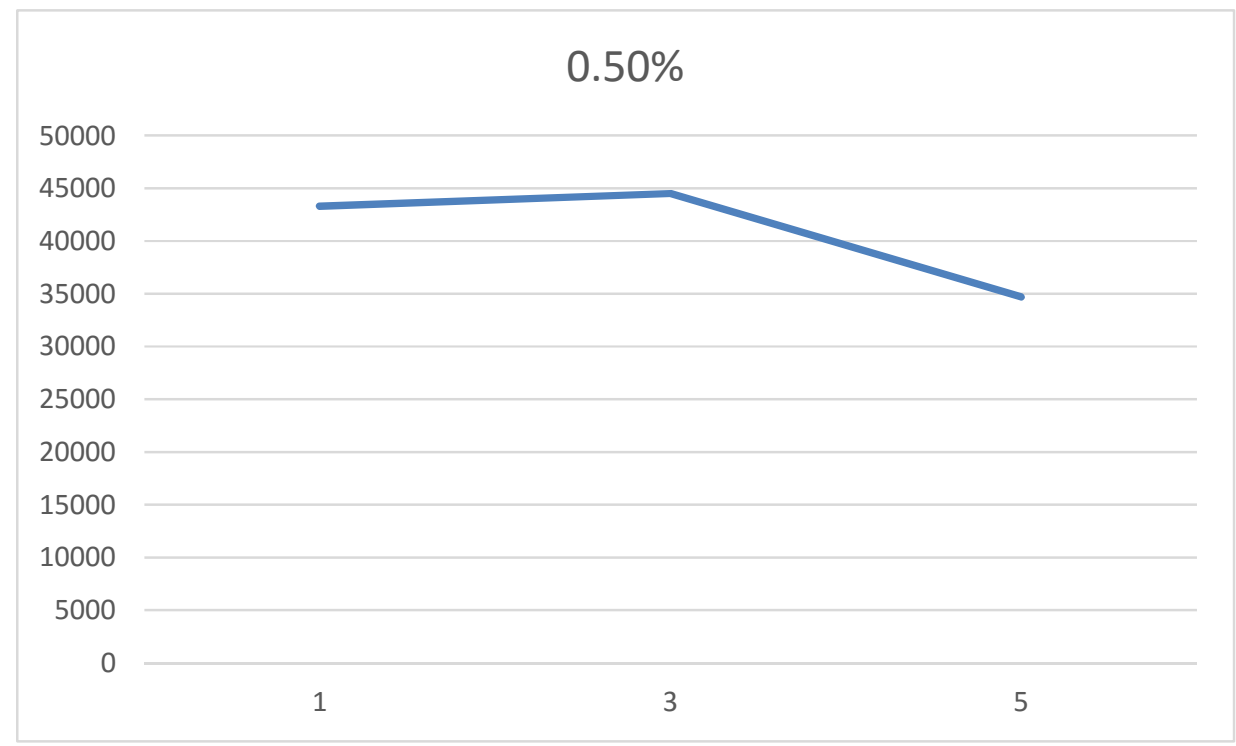

Graph -1 - The amount of tension with the change in value of fiber $0.5 \%$

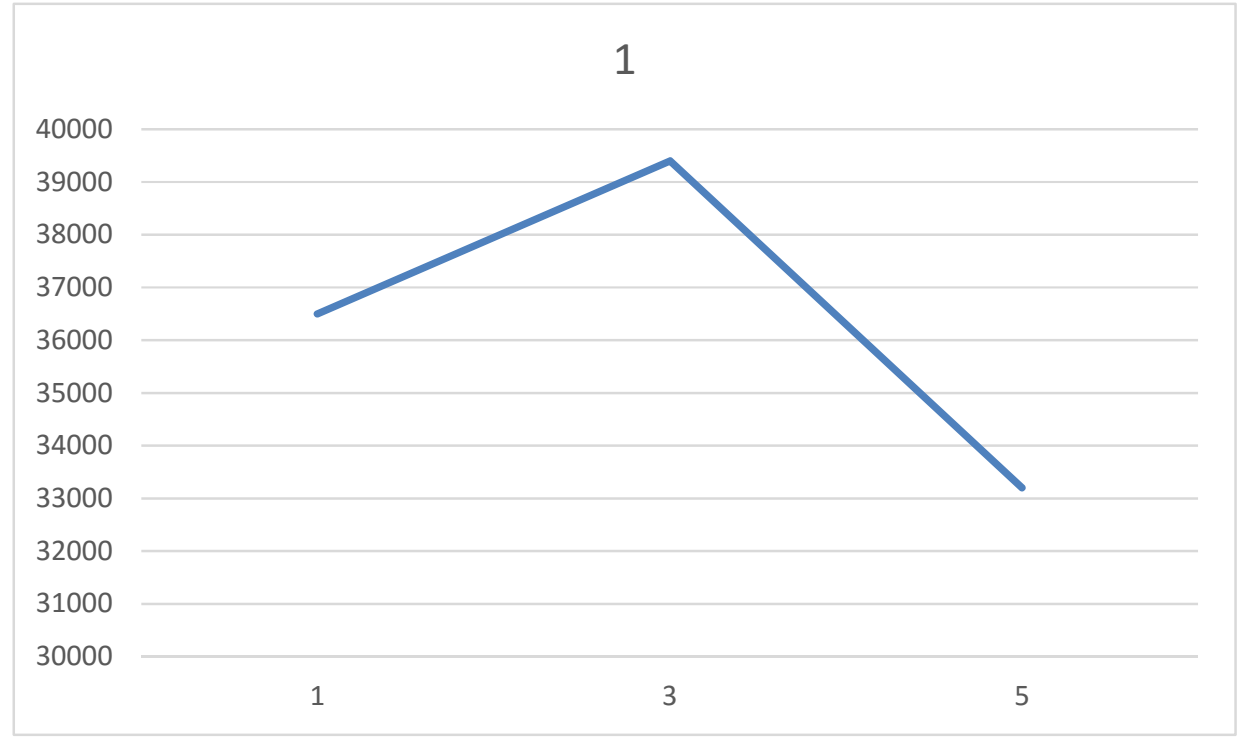

Graph - 2- The amount of tension with the change in the value of fiber $1 \%$ 


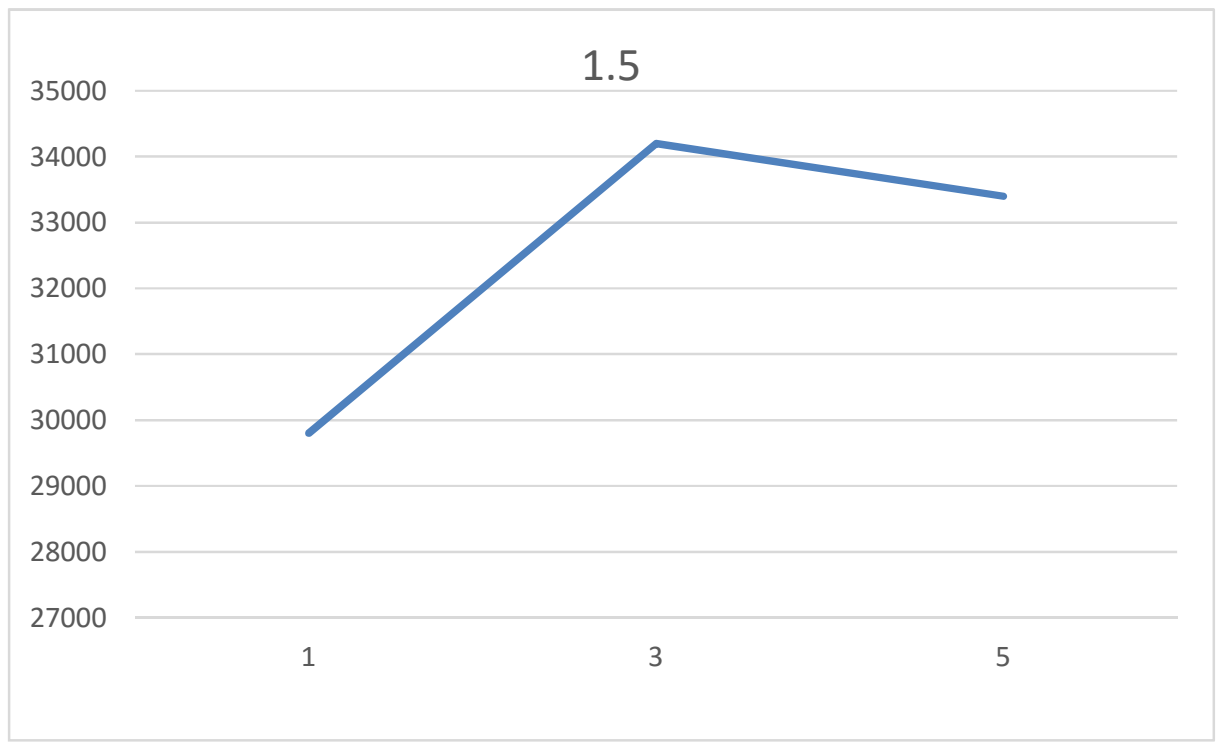

Graph - 3 - The amount of tension with the change in the value of fiber $1.5 \%$

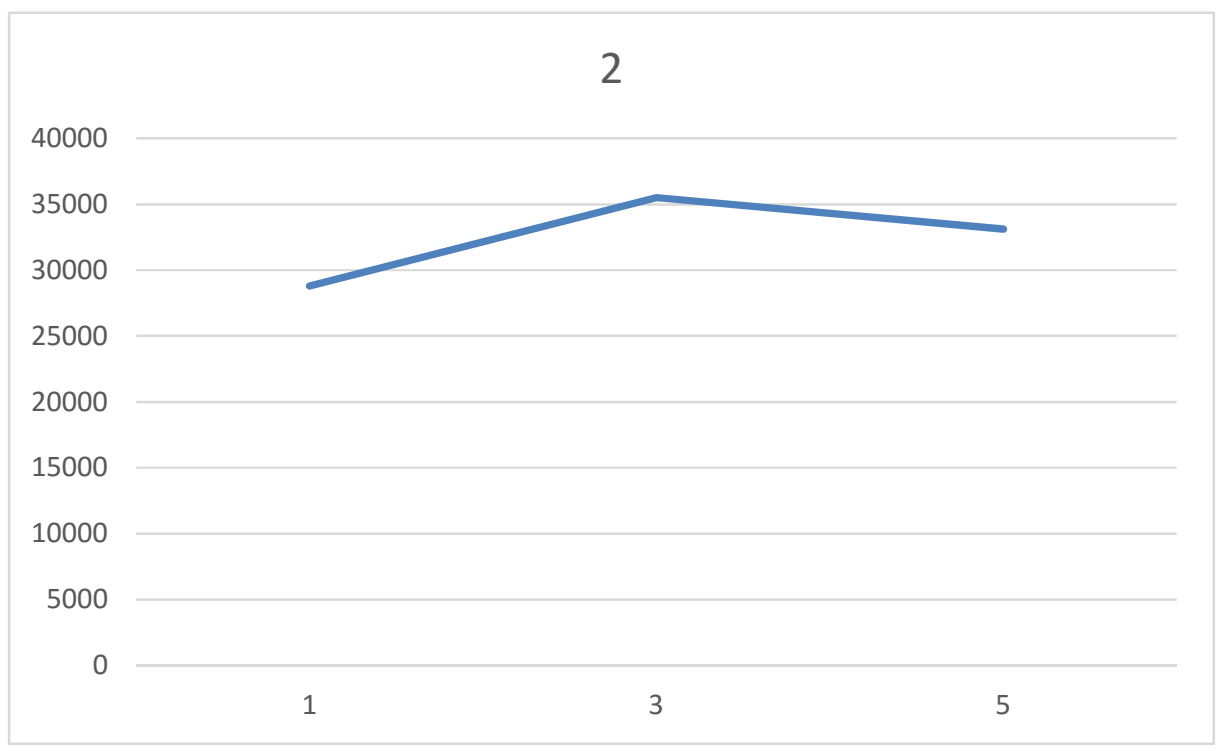

Graph -4- The amount of tension with the change in the value of fiber $2 \%$ 


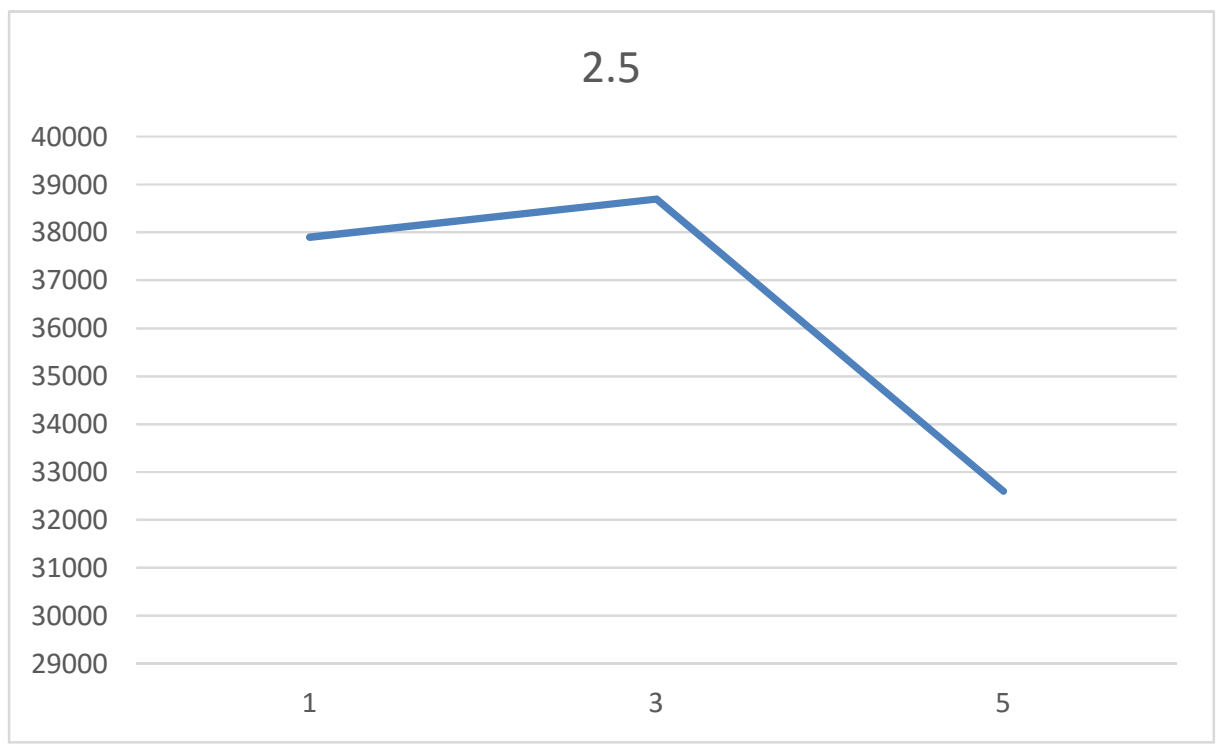

Graph -5 - The amount of tension with the change in the value of fiber $2.5 \%$

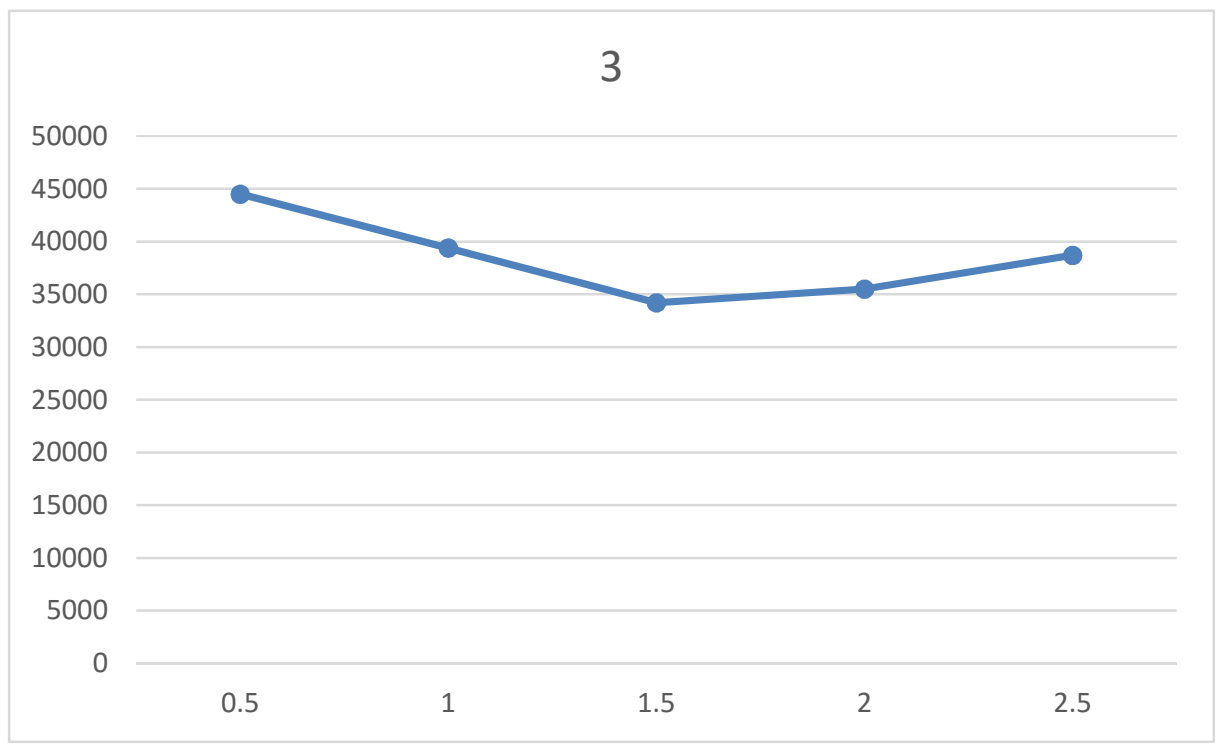

Graph -6 - The amount of tension with the change in the value of fiber $3 \%$ 


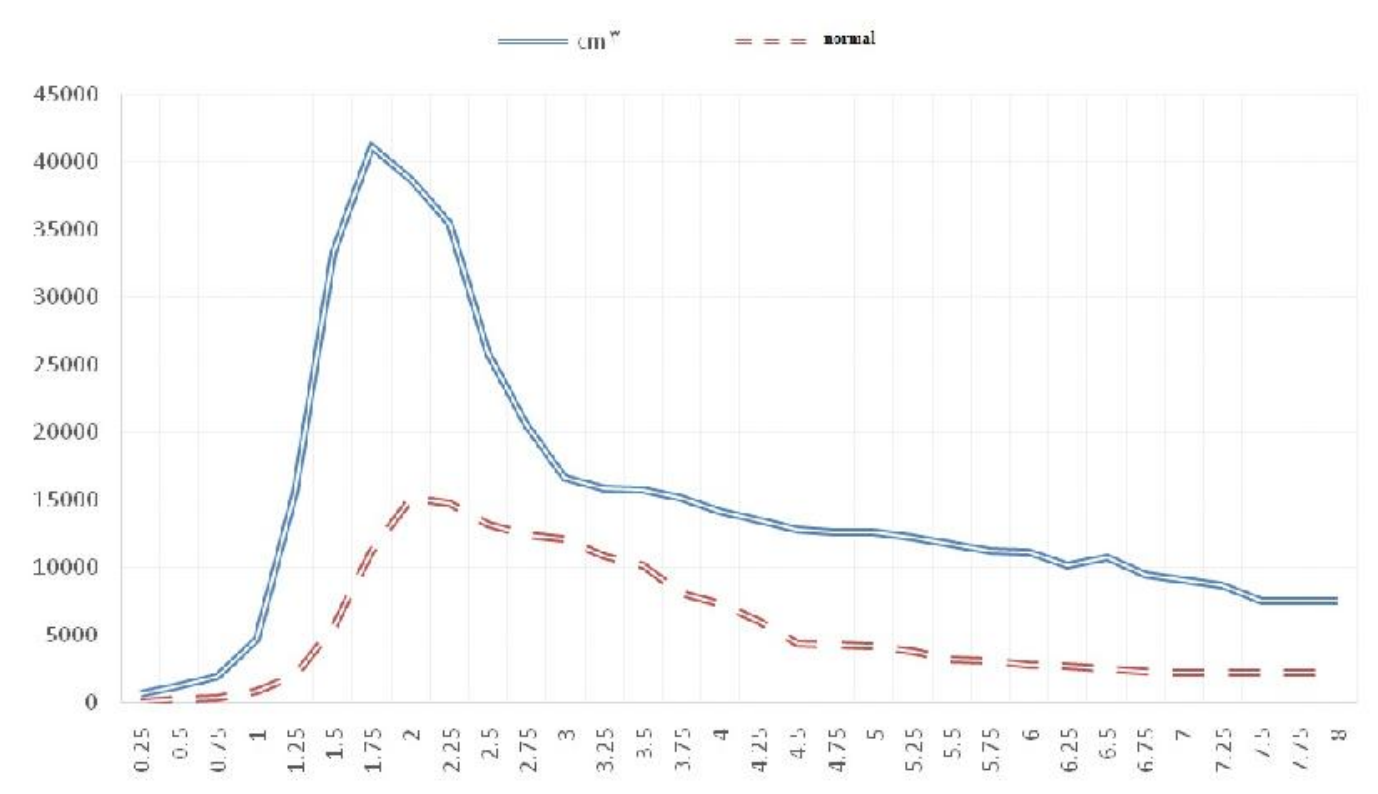

Graph -7- Comparison chart tension optimum fiber concrete with normal concrete conclusion

\section{REFERENCES}

[1] Arash Ziaeebidhendi Muslims Khoshkar and Shima Sheikh Sheibani, 1392, set Drsdbhynh Prmqavmt style mixing Drbtn style gangs, the Seventh National Congress of Civil Engineering, Zahedan, Sistan and Baluchestan University.

[2] Ashraf mention, steel fiber influence on the behavior of high strength concrete, 1390, Tabriz University.

[3] AA Ramezanianpour, doctor Mohammad Reza Shah no concrete .tknvlvzhy, 1383.antsharat Parham.

[4] Reza thereby, Ghale, E. Adili, modeling high-strength reinforced concrete beams under bending with afrp, 1387, the Fourth National Congress of Civil Engineering Tehran University.

[5] Ali Khairi, Morteza Dehghan, Mahan Ghasemi, strong fibrous concrete used in seismic design of structures, in 1388, the International Conference on Concrete Technology, University of Tabriz

[6] Daniel Reza Zadeh Eidgahi, Hooman Golkarian, M. Surag, Khusf Tavakkolizadeh, retrofitting concrete role of perlite, 1388, Conference on Civil and retrofit. 
[7] N. Banthia, M. Sappakittipakorn, 'Toughness enhancement in Steel Fibre Reinforced ConcreteThrough Fibre Hybridization ', 2007, Cementand Concrete Research.

[8] Victor C. Li, Gregore Fischer, 2002, 'Advance Composite Material in Flexural Member for Auto-Adaptive Structural Member ', Fiber Proceeding of 1th Fib Congress.

[9] D.Saradhi Babu, K. Ganesh Babu, T.H Wee, T. (2004) Properties of lightweight expanded polystyrene aggregate concretes containing fly ash. Cement and concrete research.

How to cite this article:

Kavandi $\mathrm{P}$ and Abdollahi S. Examine the impact of the changes in style of polymer fibers concrete full of strength. J. Fundam. Appl. Sci., 2016, 8(2S), 313-322. 